nephron

Practice
Nephron 2015;131:242-246

DOI: $10.1159 / 000441981$
Received: June 4, 2015

Accepted after revision: October 26, 2015

Published online: November 18, 2015

\title{
Integrating Real Time Data to Improve Outcomes in Acute Kidney Injury
}

\author{
Jamie S. Hirsch ${ }^{a, b}$ Sumit Mohan ${ }^{a, c}$ \\ a Division of Nephrology, Department of Medicine, Columbia University College of Physicians and Surgeons, \\ ${ }^{b}$ Department of Biomedical Informatics, Columbia University, and ${ }^{c}$ Department of Epidemiology, Mailman School \\ of Public Health, Columbia University, New York, USA
}

\section{Key Words}

Data Connected devices · Acute renal failure · Dialysis ·

Intensive care unit

\begin{abstract}
Critically ill patients with acute kidney injury requiring renal replacement therapy have a poor prognosis. Despite wellknown factors, which contribute to outcomes, including dose delivery, patients frequently miss the target dose and volume removal. One major barrier to effective care of these patients is the traditional dissociation of dialysis device data from other clinical information systems, notably the electronic health record (EHR). This lack of integration and the resulting manual documentation leads to errors and biases in documentation and missed opportunities to intervene in a timely fashion. This review summarizes the technological advancements facilitating direct connection of dialysis devices to EHRs. This connection facilitates automated data capture of many variables - including delivered dose, ultrafiltration rate and pressure measurements - which in turn can be leveraged for data mining, quality improvement and real-time targeted therapy adjustments. These interventions hold the promise to significantly improve outcomes for this patient population.

(c) 2015 S. Karger AG, Basel
\end{abstract}

\section{Introduction}

The desire to have automated data capture, whereby data are collected for processing and analysis without human involvement, has been around for decades. With recent technical and computational improvements, the promise of improved efficiency and quality through the capture, cataloging and analysis of high-dimensional data streams, automatic data capture has permeated myriad fields, including finance, manufacturing and marketing. Only recently, however, has the awareness and appreciation of this data source come to the wider medical community [1].

As a quantitative field, nephrology relies primarily on discrete, quantitative data and associated calculations for decision-making. In particular, renal replacement therapy (RRT) requires a battery of variables to facilitate delivered dose estimation. The treatment generates significant amounts of data, including pressure readings at various time points and locations in the circuit, changes in clear-

Contribution from the AKI and CRRT 2015 Symposium at the 20th International Conference on Advances in Critical Care Nephrology, Manchester Grand Hyatt, San Diego, Calif., USA, February 17-20, 2015.

\section{KARGER 125}

(c) 2015 S. Karger AG, Base

$1660-8151 / 15 / 1314-0242 \$ 39.50 / 0$

E-Mail karger@karger.com

www.karger.com/nef
Dr. Sumit Mohan

Division of Nephrology, Department of Medicine, Columbia University Medical Center 622 West 168th Street, PH4-124

New York, NY 10032 (USA)

E-Mailsm2206@cumc.columbia.edu 
ance and ultrafiltration rates. More recent technologies [2] have allowed for real-time measurement of delivered dialysis dose [3-5], estimates of access health [6] and the presence of recirculation [7]. In conjunction with ongoing hemodynamic monitoring, these features provide an opportunity to intervene and improve outcomes for patients requiring RRT [8].

Dialysis data, much of it continuously generated, has traditionally been captured intermittently and poorly, resulting in opportunities for selection bias and transcription error. As a result, the utility of these variables to inform quality/outcomes improvement is severely limited at this time. The imperative to improve outcomes for acute kidney injury (AKI) through real-time adjustments to patient care underlines the need for accurate and timely capture and analysis of RRT data, such as dose delivery [9]. Some of the early technological barriers - including interoperability standards, storage and processing capacity and networking infrastructure - have been eliminated [10], and the promise of connected devices and continuous data streams can now be realized to improve patient care for RRT-requiring AKI.

\section{Connected Devices in Healthcare}

Recognizing the cognitive burden of complex patients on doctors and nurses, early efforts in medical informatics focused on leveraging computers to 'ease these demands by automatically acquiring, storing and displaying patient data' [11]. The medical information bus (MIB) an IEEE interoperability standard - was the first attempt at connecting bedside devices to a database, electronic health record (EHR) system and clinical decision support [12] and demonstrate the potential of real-time automatic data capture. More recently, the American Medical Informatics Association published the guiding principles of data capture: 'automation of data capture and documentation should be optimized whenever appropriate, allowing human beings to focus on gathering and entering data that cannot be effectively collected by automated tools' [13].

Some, automated data capture systems are in existence, particularly in intensive care units and operating rooms, where identifying rapid shifts in clinical conditions are complicated by the number of devices/variables and where the potential benefits are vast $[14,15]$. Each device operates independently failing to account for other data sources [1]. Merging all the patients' data facilitates the ability to use real-time data for clinical care qual-

Integrating Real Time Data to Improve

Outcomes in AKI ity improvement and efficiencies of care. Data capture mechanisms for patients with renal disease and those requiring RRT in particular have been limited at best and largely designed to replicate manual flow sheets, thus failing to take advantage of the high volume and continuous nature of the data elements.

\section{Benefits and Challenges of Automated Data Capture}

Automatic data capture is associated with fewer errors in vital sign measurement, more timely documentation and lower charting burden for nursing, and it also raises the potential for clinical decision support using more accurate and timely data $[16,17]$. Indeed, decision support rules that rely on manual data can result in erroneous recommendations due to inaccurate or delayed data, leading to potential adverse events and eventual mistrust of the recommendations [17]. Mechanical ventilation studies have found that when respiratory therapists perform manual charting, values tend to be propagated forward for some time even after settings were, leading to incorrect values during significant portions of patient care [17]. Manual documentation is also subject to selection bias, recall bias and rounding bias, which leads to misleading data $[12,16]$.

Identification of causal relationships is possible only with accurate and timely capture of data that includes alignment of time stamps and data elements, a virtual impossibility with manual charting [1]. Subtle nuances in heart rate variability, which may predict in-hospital cardiac arrest [18], can only be recognized through efficient and automated data capture, and mortality predictions in critically ill patients are improved with the use of continuously measured hemodynamic variables [19]. Automatic data capture provides the capacity of a more complete and accurate picture of a patient's current state and trajectory.

The early use of MIB has given way to general medical interoperability standards, including the HL7 protocol, which allows for devices to connect to clinical information systems with patient matching $[1,10]$. With the increasing implementation of EHRs as a central source for patient data, in conjunction with vendor systems facilitating data capture and integration, vital sign measurements, ventilators and infusion pumps can already be connected to the EHR [20]. Further connection of devices, including dialysis machines is likely, despite the middleware, hardware, software and technical expertise-related barriers to implementation. This is being ac- 
Fig. 1. Connecting dialysis and continuous renal replacement device data to other clinical systems, such as the EHR, can facilitate the continuous flow of relevant clinical information, leading to real-time decision support and dialysis prescription adjustment, potentially improving the quality of delivered dialysis and clinical outcomes. Data capture can also facilitate secondary use, such as quality review and clinical research.

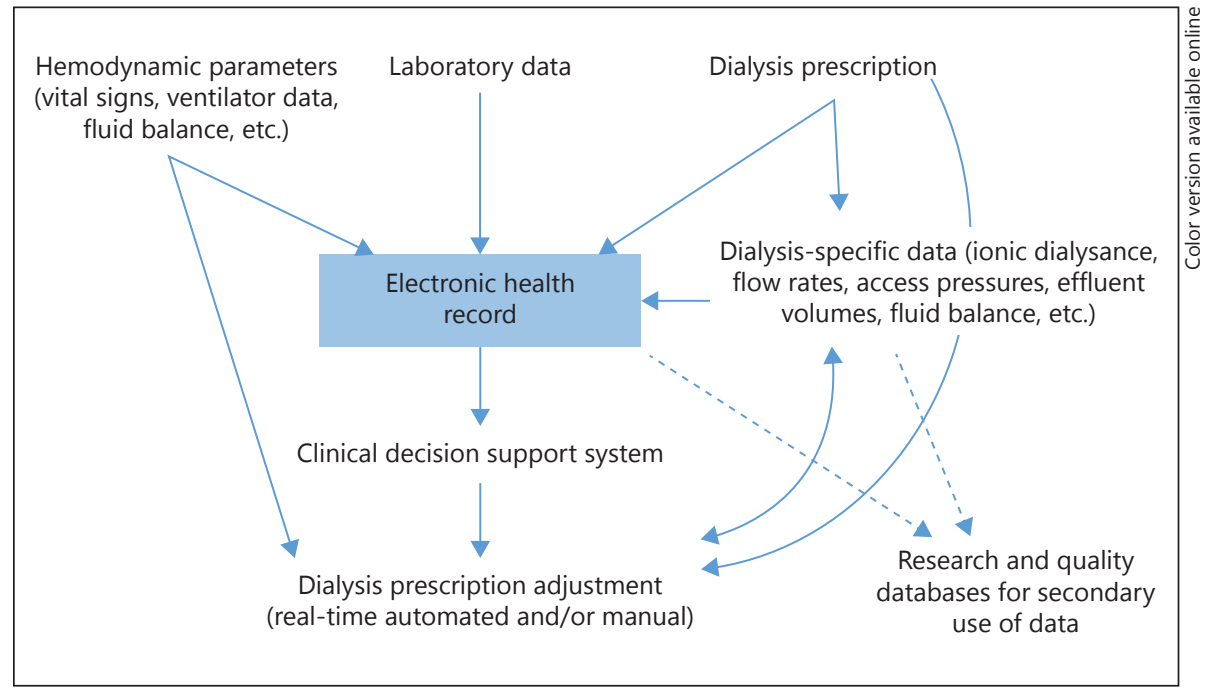

celerated by the fact that computer systems and servers have become relatively inexpensive and able to handle the large data volume generated $[10,20]$. This makes accuracy and analytics the major challenge.

Of particular concern are measurement inaccuracies arising from poor signal quality - during patient movement or handling, for example - which may lead to inappropriate decision support or alerts. Development and implementation of information technology and best engineering practices help in mitigating these concerns [1]. Indeed, machine learning algorithms that integrate multiple data types/sources can help lower false alarm rates [21].

Despite the contention that for high dimensional data such as vital sign measurements, clinicians provide effective smoothing by selecting appropriate measurements for inclusion in the record [22], this has not been shown and usually results in the loss of clinically relevant data, time trends, predictive capability and ability to perform data analytics and quality improvement $[20,23,24]$. The fear that automated systems may fail to provide accurate measurements is similarly unfounded [25].

\section{Leveraging Data Capture in Dialysis to Improve Patient Care}

Compared to vital signs and mechanical ventilators the connectivity of dialysis devices has lagged, particularly due to a lack of standardization of terminology for various parameters across devices. Given the high number of available measures and the acuity of AKI patients, there is a clear need for automated data capture from RRT devices, especially since manual collection is error-prone, prevents coordination with other clinical variables and precludes improving clinical outcomes using automated data driven clinical decision-making [26].

In the early days of hemodialysis, there was recognition that device data connected to other operational systems has significant value for patient safety and quality of care but implementation has since lagged [27]. Dialysis machines, while able to capture some data, are rarely configured to stream and incorporate data with other information, thus hampering research in adequacy measures, real-time volume management and hemodynamic predictions.

For AKI patients receiving RRT, the prescribed dose is frequently lower than recommended [28, 29], but even when the prescription is appropriate, the delivered dose is often lower still [30], particularly in critically ill patients [31]. An ongoing loss of filter capacity coupled with frequent downtime and constant hemodynamic variations in critically ill patients $[29,30,32]$, leads to highly variable intra-patient Kt measurements, similar to that in stable, chronic hemodialysis [33]. The current methodology of using effluent volumes to estimate dialysis dose in AKI is inaccurate $[28,30]$, but the lack of real-time and accurate data has limited the development of more reliable and timely estimates [34].

Fluid balance estimation for patients on RRT remains an ongoing challenge. Patients achieve target balance within $500 \mathrm{ml}$ on fewer than half of therapy days, and manual charting of ultrafiltration volumes contains inaccuracies on $60 \%$ of therapy days [35]. Accurate and me- 
ticulous volume and fluid management is crucial in AKI, as hypervolemia is associated with increased mortality $[36,37]$. The use of blood volume monitoring systems have been associated with improved ultrafiltration [38, 39] without worsening hypotensive episodes [38-40]. Matching this with cardiac output may provide further improvements [41]. Current device technology is sufficiently advanced as to capture treatment conductivity, urea kinetics, blood volume changes, thermal balance and access recirculation, among other variables [2, 42, 43], yet they are not integrated - despite the potential to result in improved outcomes [7, 44-47]. Currently available techniques for adequacy assessment include conductivitybased methods, urea sensors and spectrophotometric methods $[3,4]$. These methods can eliminate the need for blood sampling, ensure accuracy and consistency of delivered dose, detect access recirculation and enable quality assurance [48]. Ionic dialysance, for example, can accurately and constantly detect changes in clearance [5] and problems with recirculation [7] without intermittent blood sampling. When connected to EHRs, this continuous clearance monitoring can lead to real-time decision support thus facilitating the adjustment of dialysis prescriptions and timely interventions [7, 44]. Similarly, ultraviolet absorbance in dialysate can help monitor dose delivery, allowing for timely prescription adjustments $[3,49]$.

Automated collection of granular temporal data facilitates data mining, rule-making and discovery and detection of important events that effect dose and outcome [50]. Distinct temporal patterns and changes in captured variables, including pressure measurements, can further be combined and exploited to understand unique subtle- ties that may have significant impact [6]. They may help improve dose delivery, filter life, catheter and access positioning and adjustment, medication dosing and volume management, which in synergy may improve outcomes in AKI (fig. 1).

\section{Conclusion}

The care of critically ill patients with AKI requiring RRT is complex and involves the monitoring of many parameters. Connecting dialysis devices to the EHR comes with challenges, but these are being eased through implementation and investigation in other healthcare domains. Linking dialysis devices to the EHR with real-time data streams can lead to accurate and complete data capture, data mining, real-time analytics, predictive models and quality improvement. It can facilitate discovery of novel parameters that impact clinical outcomes in this complex, high-risk, critically ill population. While these technologies provider the promise of improved patient care and outcomes, their implementation will need careful study to confirm that promise and ensure the absence of negative unintended consequences.

\section{Acknowledgments}

None.

\section{Disclosure Statement}

The authors have no conflicts of interest.

\section{References}

1 Clifford GD, Long WJ, Moody GB, Szolovits P: Robust parameter extraction for decision supportusing multimodal intensive care data. Philos Trans A Math Phys Eng Sci 2009;367:411-429.

2 Ronco C, Ghezzi PM, La Greca G: The role of technology in hemodialysis. J Nephrol 2000; 12:S68-S81.

-3 Castellarnau A, Werner M, Günthner R, Jakob $\mathrm{M}$ : Real-time Kt/V determination by ultraviolet absorbance in spent dialysate: technique validation. Kidney Int 2010;78:920-925.

$\checkmark 4$ Chesterton LJ, Priestman WS, Lambie SH, Fielding CA, Taal MW, Fluck RJ, McIntyre $\mathrm{CW}$ : Continuous online monitoring of ionic dialysance allows modification of delivered hemodialysis treatment time. Hemodial Int 2006; 10:346-350
5 Ridel C, Osman D, Mercadal L, Anguel N, Petitclerc T, Richard C, Vinsonneau C: Ionic dialysance: a new valid parameter for quantification of dialysis efficiency in acute renal failure? Intensive Care Med 2007;33:460-465.

6 Ejaz AA, Komorski RM, Ellis GH, Munjal S: Extracorporeal circuit pressure profiles during continuous venovenous haemofiltration. Nurs Crit Care 2007;12:81-85.

7 Tan J, Mohan S, Herbert L, Anderson H, Cheng JT: Identifying hemodialysis catheter recirculation using effective ionic dialysance. ASAIO J 2012;58:522-525.

8 Kusiak A, Dixon B, Shah S: Predicting survival time for kidney dialysis patients: a data mining approach. Comput Biol Med 2005;35: 311-327.
9 Hug CW, Szolovits P: ICU acuity: real-time models versus daily models. AMIA Annu Symp Proc 2009;2009:260-264.

10 Fonseca T, Ribeiro C, Granja C: Vital signs in intensive care: automatic acquisition and consolidation into electronic patient records. J Med Syst 2009;33:47-57.

11 Gardner RM, West BJ, Pryor TA, Larsen KG, Warner HR, Clemmer TP, Orme JF Jr: Computer-based ICU data acquisition as an aid to clinical decision-making. Crit Care Med 1982;10:823-830.

12 Gardner RM, Hawley WL, East TD, Oniki TA, Young HF: Real time data acquisition: recommendations for the medical information bus (MIB). Int J Clin Monit Comput 1991-1992;8:251-258. 
13 Cusack CM, Hripcsak G, Bloomrosen M, Rosenbloom ST, Weaver CA, Wright A, Vawdrey DK, Walker J, Mamykina L: The future state of clinical data capture and documentation: a report from AMIA's 2011 policy meeting. J Am Med Inform Assoc 2013;20:134-140.

14 Weil MH, Shubin H, Rand W: Experience with a digital computer for study and improved management of the critically ill. JAMA 1966;198:1011-1016.

15 Celi LA, Mark RG, Stone DJ, Montgomery RA: 'Big data' in the intensive care unit. Closing the data loop. Am J Respir Crit Care Med 2013;187:1157-1160.

-16 Taenzer AH, Pyke J, Herrick MD, Dodds TM, McGrath SP: A comparison of oxygen saturation data in inpatients with low oxygen saturation using automated continuous monitoring and intermittent manual data charting. Anesth Analg 2014;118:326-331.

$\checkmark 17$ Vawdrey DK, Gardner RM, Evans RS, Orme JF Jr, Clemmer TP, Greenway L, Drews FA: Assessing data quality in manual entry of ventilator settings. J Am Med Inform Assoc 2007; 14:295-303.

18 Ong ME, Lee Ng CH, Goh K, Liu N, Koh ZX, Shahidah N, Zhang TT, Fook-Chong S, Lin Z: Prediction of cardiac arrest in critically ill patients presenting to the emergency department using a machine learning score incorporating heart rate variability compared with the modified early warning score. Crit Care 2012; 16:R108.

19 Mayaud L, Lai PS, Clifford GD, Tarassenko L, Celi LA, Annane D: Dynamic data during hypotensive episode improves mortality predictions among patients with sepsis and hypotension. Crit Care Med 2013;41:954-962.

20 Blount M, Ebling MR, Eklund JM, James AG, McGregor C, Percival N, Smith KP, Sow D: Real-time analysis for intensive care: development and deployment of the artemis analytic system. IEEE Eng Med Biol Mag 2010;29: 110-118.

$21 \mathrm{Li}$ Q, Clifford GD: Signal quality and data fusion for false alarm reduction in the intensive care unit. J Electrocardiol 2012;45:596-603.

-22 Sapo M, Wu S, Asgari S, McNair N, Buxey F, Martin N, Hu X: A comparison of vital signs charted by nurses with automated acquired values using waveform quality indices. J Clin Monit Comput 2009;23:263-271.

-23 Bai Y, Do DH, Harris PR, Schindler D, Boyle NG, Drew BJ, Hu X: Integrating monitor alarms with laboratory test results to enhance patient deterioration prediction. J Biomed Inform 2015;53:81-92.

-24 Hug CW, Clifford GD, Reisner AT: Clinician blood pressure documentation of stable intensive care patients: an intelligent archiving agent has a higher association with future hypotension. Crit Care Med 2011;39:10061014.
Cunningham S, Deere S, Elton RA, McIntosh $\mathrm{N}$ : Comparison of nurse and computer charting of physiological variables in an intensive care unit. Int J Clin Monit Comput 1996;13: 235-241.

26 Savage B, Marquardt GW, Paolini F, Schlaeper C: Information technology and acute dialysis. Curr Opin Crit Care 2002;8:544-548.

27 Watson BW, Morrison AP, Cattell WR, Mackenzie JC: A bedside monitor for use with central dialysate supply. Lancet 1967;2:922924.

28 Lyndon WD, Wille KM, Tolwani AJ: Solute clearance in CRRT: prescribed dose versus actual delivered dose. Nephrol Dial Transplant 2012;27:952-956

29 Venkataraman R, Kellum JA, Palevsky P: Dosing patterns for continuous renal replacement therapy at a large academic medical center in the United States. J Crit Care 2002;17: 246-250.

30 Claure-Del Granado R, Macedo E, Chertow GM, Soroko S, Himmelfarb J, Ikizler TA, Paganini EP, Mehta RL: Effluent volume in continuous renal replacement therapy overestimates the delivered dose of dialysis. Clin J Am Soc Nephrol 2011;6:467-475.

31 Schiffl H: Disease severity adversely affects delivery of dialysis in acute renal failure. Nephron Clin Pract 2007;107:c163-c169.

32 Beitland S, Sunde K, Moen H, Os I: Variability in uremic control during continuous venovenous hemodiafiltration in trauma patients. Crit Care Res Pract 2012;2012:869237.

33 Lambie SH, Taal MW, Fluck RJ, McIntyre CW: Analysis of factors associated with variability in haemodialysis adequacy. Nephrol Dial Transplant 2004;19:406-412.

34 Macedo E, Claure-Del Granado R, Mehta RL: Effluent volume and dialysis dose in CRRT: time for reappraisal. Nat Rev Nephrol 2011;8: $57-60$.

35 Steen J, Schell-Chaple H: 657: identifying improvement opportunities through quality and safety monitoring of continuous renal replacement therapy (CRRT) practice. Crit Care Med 2011;39:181.

36 Grams ME, Estrella MM, Coresh J, Brower RG, Liu KD; National Heart, Lung, and Blood Institute Acute Respiratory Distress Syndrome Network: Fluid balance, diuretic use, and mortality in acute kidney injury. Clin J Am Soc Nephrol 2011;6:966-973.

37 Teixeira C, Garzotto F, Piccinni P, Brienza N, Iannuzzi $\mathrm{M}$, Gramaticopolo S, Forfori $\mathrm{F}$, Pelaia P, Rocco M, Ronco C, Anello CB, Bove T, Carlini M, Michetti V, Cruz DN; NEFROlogia e Cura INTensiva (NEFROINT) Investigators: Fluid balance and urine volume are independent predictors of mortality in acute kidney injury. Crit Care 2013;17:R14.
38 du Cheyron D, Lucidarme O, Terzi N, Charbonneau P: Blood volume- and blood temperature-controlled hemodialysis in critically ill patients: a 6-month, case-matched, open-label study. Blood Purif 2010;29:245-251.

39 Merouani A, Kechaou W, Litalien C, Ducruet T, Jouvet P: Impact of blood volume monitoring on fluid removal during intermittent hemodialysis of critically ill children with acute kidney injury. Nephrol Dial Transplant 2011; 26:3315-3319.

40 du Cheyron D, Terzi N, Seguin A, Valette X, Prevost F, Ramakers M, Daubin C, Charbonneau P, Parienti JJ: Use of online blood volume and blood temperature monitoring during haemodialysis in critically ill patients with acute kidney injury: a single-centre randomized controlled trial. Nephrol Dial Transplant 2013;28:430-437.

-41 Mailloux PT, Friderici J, Freda B, McGee WT: Establishing goals of volume management in critically ill patients with renal failure. J Nephrol 2012;25:962-968.

42 Ricci Z, Ronco C: Information technology for CRRT and dose delivery calculator. Contrib Nephrol 2007;156:197-202.

-43 Ronco C, Brendolan A, Bellomo R: Online monitoring in continuous renal replacement therapies. Kidney Int Suppl 1999;56:S8-S14.

44 Mohan S, Madhrira M, Mujtaba M, Agarwala R, Pogue V, Cheng JT: Effective ionic dialysance/blood flow rate ratio: an indicator of access recirculation in arteriovenous fistulae. ASAIO J 2010;56:427-433.

45 Moissl U, Arias-Guillén M, Wabel P, Fontseré N, Carrera M, Campistol JM, Maduell F: Bioimpedance-guided fluid management in hemodialysis patients. Clin J Am Soc Nephrol 2013;8:1575-1582.

46 Leypoldt JK, Cheung AK, Steuer RR, Harris $\mathrm{DH}$, Conis JM: Determination of circulating blood volume by continuously monitoring hematocrit during hemodialysis. J Am Soc Nephrol 1995;6:214-219.

47 Gabrielli D, Krystal B, Katzarski K, Youssef M, Hachache T, Lopot F, Lasseur C, Gunne T, Draganov B, Wojke R, Gauly A: Improved intradialytic stability during haemodialysis with blood volume-controlled ultrafiltration. J Nephrol 2009;22:232-240.

48 Daugirdas JT, Tattersall JE: Automated monitoring of hemodialysis adequacy by dialysis machines: potential benefits to patients and cost savings. Kidney Int 2010;78:833-835.

-49 Tomson R, Fridolin I, Uhlin F, Holmar J, Lauri K, Luman M: Optical measurement of creatinine in spent dialysate. Clin Nephrol 2013; 79:107-117.

50 Bellazzi R, Larizza C, Magni P, Bellazzi R: Temporal data mining for the quality assessment of hemodialysis services. Artif Intell Med 2005;34:25-39. 